\title{
Social Meaning and the Possible Societal Responses to the Public Health Problem of Tuberculosis - Part 1
}

\author{
Vikas Bajpai ${ }^{1 *}$, Anoop Saraya ${ }^{2}$, Suman Bhasker ${ }^{3}$ \\ ${ }^{1}$ Centre for Social Medicine and Community Health, Jawaharlal Nehru University, New Delhi - 110067. \\ ${ }^{2}$ Department of Gastroenterology and Human Nutrition, All India Institute of Medical Sciences, New Delhi - 110029. \\ ${ }^{3}$ Department of Radiation Oncology, All India Institute of Medical Sciences, New Delhi.
}

\section{A B STRACT}

Understanding the social meaning and perceptions of a disease are the key to designing epidemiologically effective disease control programs. Tuberculosis continues to remain an important public health problem across the world, as also in India. This paper traces how the social meaning of tuberculosis has changed over the centuries under the impact of the advances in the knowledge about the disease, and how these changing perceptions have determined the societal responses to tuberculosis. The paper has been organized in two parts. Part 1 deals with the epidemiological dimensions of tuberculosis in India, a brief historiography of tuberculosis and a discussion on how social meaning of a disease is formed with a focus on tuberculosis. Part two traces the societal responses to tuberculosis in India and an analysis of the epidemiological aspects of the National Tuberculosis Program (NTP) and the Revised National Tuberculosis Program (RNTCP).

Key words: Tuberculosis, RNTCP, NTP, Epidemiology, Societal

\section{INTRODUCTION}

There is little gainsaying in stating that public health interventions are as much a social, economic and political intervention as they are application of medical technology for improving the health of the society at large by putting in place the requisite delivery mechanisms. Rudolph Virchow put this most succinctly thus - "Medicine is a social science, and politics nothing but medicine at a larger scale". ${ }^{1}$

A disease control program cannot stand only on the cutting edge biomedical tools to intervene in the transmission and pathogenesis of disease; it has to ensure that these are affordable, culturally acceptable to the people, satisfy their felt needs, and are amenable to a wider coverage as also being effective in preventing and curing the disease. These requirements entail that we understand the social meaning

Address for correspondence:

Mobile: 9810275314

E-mail: drvikasbajpai@gmail.com

DOI: 10.5530/ijmedph.3.2011.6 of a disease as engendered by its specific social, economic, political, biological and epidemiological context, and there upon develop public health responses which are capable of addressing these myriad aspects of the disease as a public health problem. Making light of these requirements and reposing excessive faith in the potential of biomedical tools is to sow the seeds of failure at the very inception of a public health program. In this article we attempt to understand the social meaning and the possible societal responses (disease control programs being one among them) to the public health problem of tuberculosis.

Before we go into examining the factors that give tuberculosis its social meaning and the possible societal responses, it is instructive here to have a detailed look at the epidemiological dimensions of tuberculosis in India.

\section{EPIDEMIOLOGICAL DIMENSIONS OF TUBERCULOSIS}

Tuberculosis is a communicable disease caused by a bacterium called Mycobacterium Tuberculosis. The bacterium can afflict any part/organ of the body; however it is the 
infection of the lung i.e. pulmonary TB (PTB) which is of greatest significance from public health point of view because it may lead to bacillary form of tuberculosis i.e. when the patient starts disseminating TB bacterium in sputum or cough in the form of tiny droplets which may be inhaled by non-infected persons, especially in crowded conditions of living or working. Non - pulmonary forms of tuberculosis though may result in serious forms of medical presentation, but are never a cause of the spread of tubercular infection.

India carries with it dubious distinction of being the country with the highest burden of tuberculosis in the World. Of the total 9.4 million cases of TB that occur worldwide, India account for 1.98 million cases i.e. a fifth of all the cases and it ranks $17^{\text {th }}$ out of a total of 22 countries in terms of TB incidence rate. ${ }^{2}$ It is estimated that about $40 \%$ of the population in the country is infected with TB bacillus. The government of India had a nationwide survey conducted between 2000 and 2003 for the estimation of Annual Risk of Tuberculosis Infection (ARTI), based on which the annual incidence of TB is calculated in India. While the total number of annual TB cases in India are estimated at the rate of $1.5 \%$ of the population, the new smear positive cases are of the tune of 75 per 100, 000 population. ${ }^{3}$ There were estimated 3.8 million bacillary tuberculosis cases in the country in $2000{ }^{4,5}$ However, WHO has given recent estimates to be in the vicinity of 2.186 million. Table 1 below summarizes the incidence and prevalence of TB in India:

\section{NEW SPUTUM POSITIVE (NSP) CASES}

From public health point of view it is the sputum positive cases that are of greatest significance for reasons already mentioned above. It is now estimated that the detection of NSP cases under RNTCP has crossed $70 \%$ of the total inflow of NSP cases every year. This however still leaves a deficit of $30 \%$ in sputum positive cases which has repercussions for control over the disease. Figure 1 below gives the numbers of the total estimated NSP cases, and $70 \%$ level of estimated NSP cases over last one decade.

The age composition of these cases is also a matter of worry because TB afflicts people most in their economically most productive years i.e. between 15-55 yrs as can be seen from figure $2 .{ }^{6}$ Apparently RNTCP has made little dent in this age composition during the last one decade. In fact the proportion of patients in the higher age groups beyond $55 \mathrm{yrs}$, which form the main reservoir of infection, has increased marginally.

All available data regarding the incidence and prevalence of tuberculosis shows that it afflicts males disproportionately more than the females. In fact the male to female ratio over the last decade has varied between 2.0 and 2.2. ${ }^{7}$ However, gender perception of the disease places the female patients at a particular disadvantage due to greater stigma and lower prioritization of women's health. ${ }^{8}$ As women in the reproductive and economically active years are the most common victims, it has wider repercussions for children and families. ${ }^{9}$

As has become the unfortunate trend with all official health related data in India, there is little data available on class co-relates of the incidence and prevalence of tuberculosis in India. However, it is an undisputed fact that tuberculosis is primarily a disease of poverty and perhaps that explains why our policy makers let a pioneering program like the National Tuberculosis Program (NTP) languish for so many years which resulted in unchanged incidence and prevalence of TB in the country since the fifties, until of course the WHO, propelled by re-emergence of TB in the West along with the pandemic of HIV - AIDS, declared TB to be a global emergency in $1993 .{ }^{10}$ Documentation of class co-relates of a disease is also important form the viewpoint

Table 1: Estimated burden of tuberculosis in India

\begin{tabular}{lcc}
\hline & Number (Millions) (95\% Cl) & Rate Per 100,000 Persons (95\% Cl) \\
\hline Incidence (2009 WHO estimate) & $1.982(1.6-2.4)$ & 168 \\
All cases & 0.885 & 75 \\
AFB smear-positive & & $165(126-204)^{\dagger}$ \\
Period Prevalence (2000 Gol estimate) ${ }^{\dagger}$ & $1.7(1.3-2.1)$ & $369(272-457)^{\dagger}$ \\
AFB positive & $3.8(2.8-4.7)$ & 443 \\
Bacillary* & 4.468 & 283 \\
Prevalence, all cases (2000 WHO estimate) & \\
Prevalence, all cases (2007 WHO estimate) & 3.304 & 185 \\
Prevalence, all cases (2009 WHO estimate) & $2.186(1.044-3.739)$ & \\
\hline
\end{tabular}

Source: TB India 2010: RNTCP Status Report.

*Defined as a person with at least one AFB smear positive by sputum microscopy, or at least one sputum culture positive for M. Tuberculosis.

${ }^{\dagger}$ Prevalence rate calculated from estimated number of persons with disease in 2000 , divided by 2000 population estimate. 


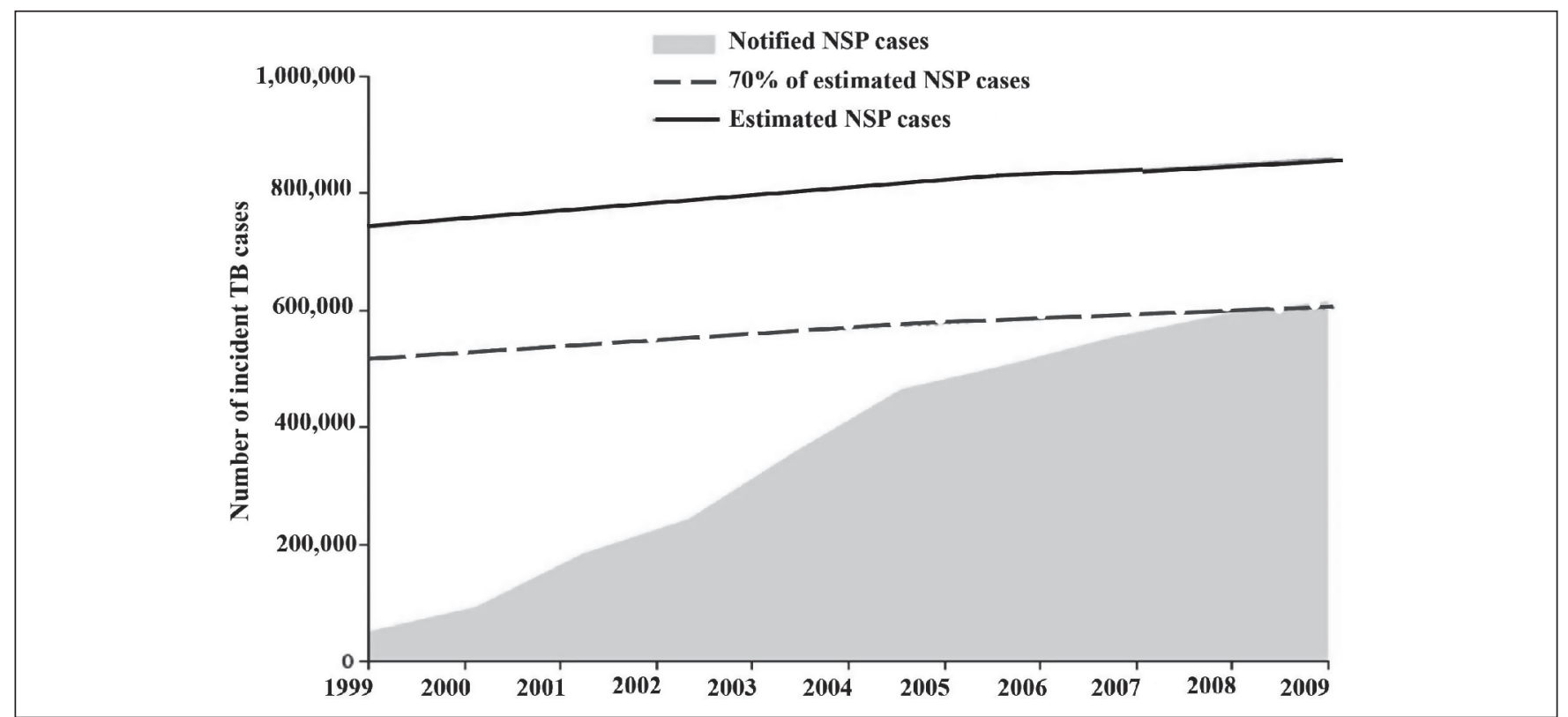

Figure 1: Total new smear positive TB cases notified under RNTCP, relative to the total number of estimated new smear-positive cases (stable at 75 NSP cases per 100,000).

Source: TB India 2010: RNTCP Status Report.

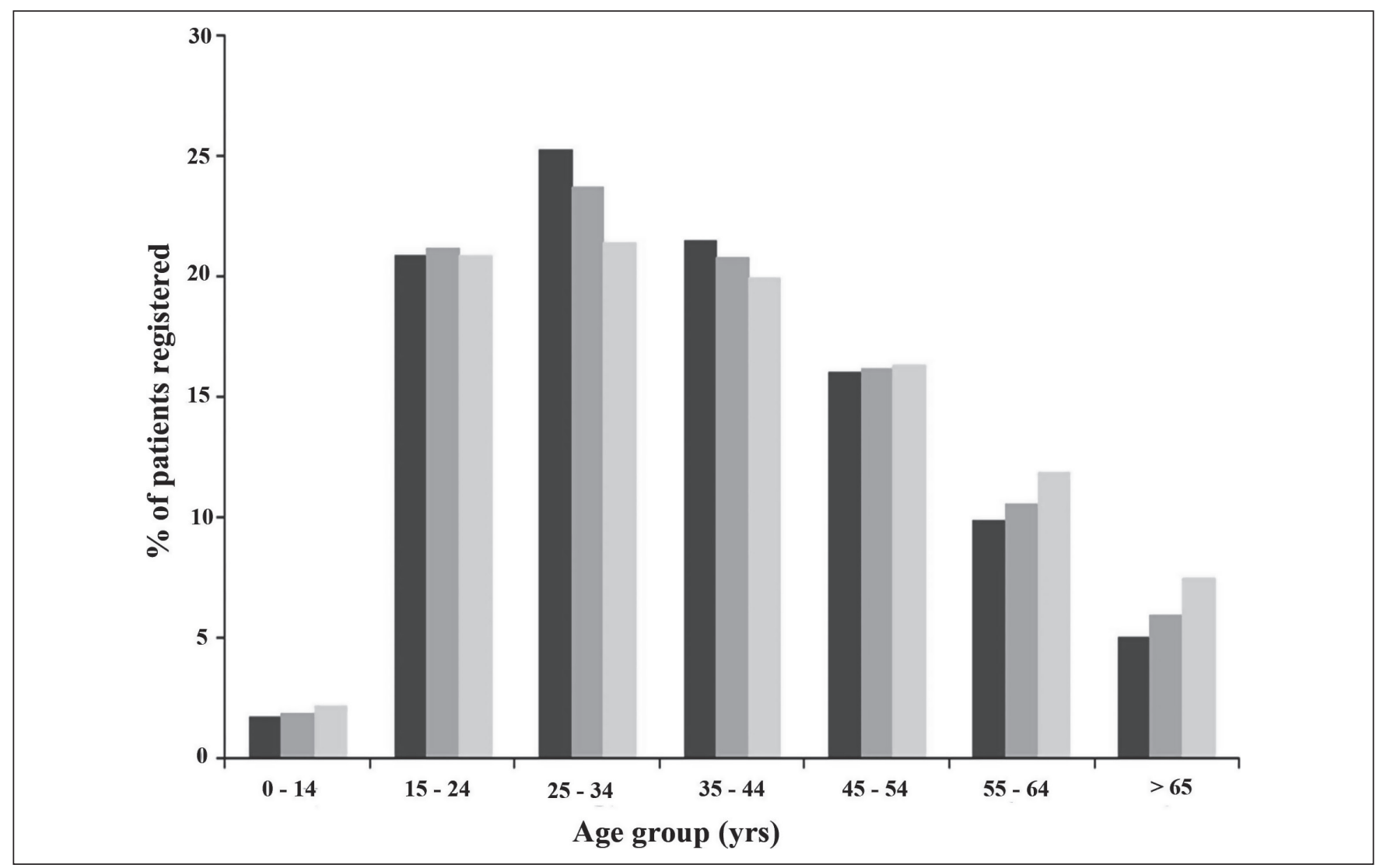

Figure 2: Proportion of total NSP case notifications from each age group, 2001, 2005, 2009.

Source: TB India 2010: RNTCP Status Report.

of building in program components that shall address the specific felt needs of the affected sections, as also the epidemiologically determined needs. The felt needs for a well off and poor TB patients are bound to be different, requiring different kinds of programmatic interventions at different levels. 


\section{VARIATION AMONG TUBERCULOSIS CASES}

In a study emblematic of India's rich tradition in tuberculosis research, Raj Narain and his colleagues had shown considerable variation in the types of tuberculosis cases in the community. Data from two successive surveys, 18 months apart, for tuberculosis prevalence in randomly selected villages in Bangalore district of Karnataka (south India) showed that - "a case of pulmonary tuberculosis does not represent a single uniform entity, but rather embraces cases of several types, differing considerably in their mortality experience, tuberculin sensitivity, results of X-ray and sputum examinations, and in the reliability of their diagnosis." Changes were found to appear in different types of tuberculosis cases over a period of time in comparison to the initial picture. The authors of the study opined - "in spite of the great need and importance of a single straightforward definition of a case, no such definition is suitable for all situations; there is no other option but to continue to use more than one definition." 11

With respect to the programmatic requirements of the then operating National Tuberculosis Program the authors suggested that - "scanty positives by smear should not be regarded as cases, and that sputum-negative X-ray casesshould not be treated." "They emphasized the "need for further study" as to the value of international comparison based on a single working definition given by WHO Expert Committee on Tuberculosis in 1964. ${ }^{11}$

As far back as 1949, Cedric Northrop et. al. also attested to "lack of any clear-cut definition of what may be considered a reportable case of tuberculosis." 12 Lest this study might be considered too antiquated to be considered part of modern knowledge on TB; Joshi et. al., while deliberating on the "Problems in Laboratory Diagnosis of Tuberculosis" found that in $58.53 \%$ of the cases examined by them there was a discrepancy between the clinical findings, the laboratory reports and the outcomes in patients. ${ }^{13}$

The epidemiological variability in the type of tuberculosis cases, as we shall see in the subsequent section, has direct implication on the outcome in a case of TB.

\section{POSSIBLE OUTCOMES IN A CASE OF TUBERCULOSIS}

\section{Spontaneous recovery}

It is perhaps less widely known and even less propagated that spontaneous recovery is one of the natural and not so rare an outcome of a tuberculosis case. There are many clinical reports which attest to this phenomenon. ${ }^{14,15,16,17}$
Repeated surveys conducted by the National Tuberculosis Institute (NTI) in the rural areas in the sixties had shown that as much as one third of the sputum positive PTB cases recovered spontaneously in the absence of any proper antitubercular treatment. ${ }^{18}$ Baily and co-workers showed spontaneous recovery in about $30 \%$ of the patients in a series who had been treated with drugs to which their tubercle bacilli were resistant. ${ }^{19}$ Likewise Gothi et.al. demonstrated that 22 to $25 \%$ of sputum positive cases showed sputum conversion in two repeated surveys without any proper treatment. ${ }^{20}$

\section{Cure from short course chemotherapy Defaulters}

There are quite a few studies that have recorded cure rates ranging from $66 \%$ to $74 \%$ in patients who defaulted in treatment during the NTP. ${ }^{21,22,23,24,25}$

\section{Defaulters and those satisfactorily treated}

In one series of 285 patients who were treated under the district tuberculosis program of NTP, only 33\% patients completed the required treatment; nevertheless the cure rate was as high as $72 \%{ }^{26}$ Some other studies with short course chemotherapy (SCC) under NTP, with a mixture of defaulters and those treated satisfactorily produced cure rates as high as $90 \%{ }^{27}$ to $96 \%{ }^{28}$

\section{Disease progression}

It is needless to say that there always are some cases in which disease progresses leading ultimately in death. Nevertheless, here also it is important to note whether death occurred due to the presence of any other co-morbid condition like malnutrition, diabetes, any other chest infection or AIDS or because of the pathogenicity of the tuberculosis bacillus.

Spontaneous recovery, high cure rates even in defaulter patients and a mixture of defaulter as well as those who completed the SCC satisfactorily, points to the possibility that all TB patients need not have the same kind of treatment. Therapeutic options could range between no treatment, a shorter duration of chemotherapy and a full course of SCC, provided the criterion could be devised upon sufficient research to demarcate between patients who would benefit from these respective lines of treatment.

\section{PUBLIC HEALTH PROBLEM OF TUBERCULOSIS}

The substantial mortality due to TB constitutes only a part of the public health problem of TB. TB accounts for $17.6 \%$ of all deaths due to communicable diseases and 3.5\% of all causes of mortality. ${ }^{4}$ At least until the Revised National Tuberculosis Control Program (RNTCP) came into its own 
it was widely held that the overall tuberculosis deaths annually in the country were more than half a million and until the beginning of this century approximately 25 million lives had been lost since 1947..$^{29}$ Even now TB is responsible for 330, 000 deaths each year, a thousand deaths every day and 2 deaths every three minutes. ${ }^{5}$

Emergence of tuberculosis in association with the global pandemic of HIV - AIDS has given the disease a renewed sense of urgency, especially in the West, which has resulted in newer global initiative in the form of DOTS (directly observed treatment short course) administered through nationally supervised tuberculosis control programs in different countries. ${ }^{30,31}$ People infected with TB bacillus have $10 \%$ lifetime chance of developing TB, but with HIV co-infection their chance of developing TB increases by $10 \%$ every year. ${ }^{32}$

Apart from concomitant infection with HIV - AIDS and $\mathrm{TB}$, the other raison detour given for DOTS was the emergence of multi-drug resistant tuberculosis (MDR-TB). It was anticipated that due to high rates of default in case of non-supervised treatment there shall be greater prevalence and incidence of multi-drug resistant tuberculosis. However, all available evidence from India goes to show that the prevalence of MDR-TB in new smear positive cases of TB is $<3 \%$ while in smear-positive PTB cases with previous treatment; prevalence is between 12 to $17 \%$. Reviews of studies with representative samples do not betray any rise in the prevalence of MDR-TB, thus proving the dooms day scenarios in this case totally wrong. ${ }^{33}$

A much bigger proportion of public health problem of tuberculosis results from the impact that the disease has on its victims in terms of its pathological effects, shattered economic life of individuals and families, the associated social stigma of the disease that tends to stick for a life time, the direct and indirect economic costs to the society and the residual effects of the disease even upon cure. Poverty is the biggest curse associated with TB. To put it in the words of Ian Smith - "Tuberculosis and poverty go hand in hand - people who are poor get tuberculosis, and people who get tuberculosis become poor." 32

In essence, in the words of Banerii, tuberculosis is quintessentially a problem of 'human suffering. ${ }^{34}$ The term 'human suffering' here is more than just an altruistic expression of the problem; It has definite epidemiological connotation. Putting TB as a problem of 'human suffering' foregrounds the suffering of the patients in a manner as to demand that a program to control the public health problem of tuberculosis be firmly rooted in strategies focused on socio-political values while effectively subordinating technology to serve the needs of the patients, as against a program that emphasizes 'motivational manipulation' of the patients to sub-serve a pre-determined technological intervention handed down by the policy planners in a top down approach. We shall elaborate on the meaning of this a while later.

Even WHO has observed that in tackling the menace of tuberculosis, improved methods of diagnosis and treatment might as well mean little if there were to be no alleviation of attendant risk factors which cause latent tuberculosis infection to progress to frank disease. These risk factors have broadly been categorized as biomedical (such as HIV infection, diabetes, tobacco, malnutrition, silicosis, malignancy), environmental (indoor air pollution, ventilation) or socioeconomic (crowding, urbanization, migration, poverty). Among these poverty can be found to be at the root of malnutrition, indoor air pollution, migration directly and is a very strong determining factor for the outcome of HIV infection, diabetes, tobacco, silicosis, malignancy, crowding and urbanization. As we shall see below that this cardinal truth has played out during the course of the history of tuberculosis over the centuries.

\section{LONG TERM TRENDS IN TUBERCULOSIS}

The history of public health programs for the control of tuberculosis is relatively new compared to the overall history of tuberculosis in the world. It was not untill 1882 that mycobacterium tuberculosis was discovered by Robert Koch and the BCG vaccine (the first specific protective measure against TB) was used for the first time in $1921 .{ }^{35}$ However, as is evident from figure 3 , much of the decline in mortality due tuberculosis had already happened even before the discovery of the TB bacterium or the institution of the first anti-tuberculosis measures. It is important to understand the factors behind this decline.

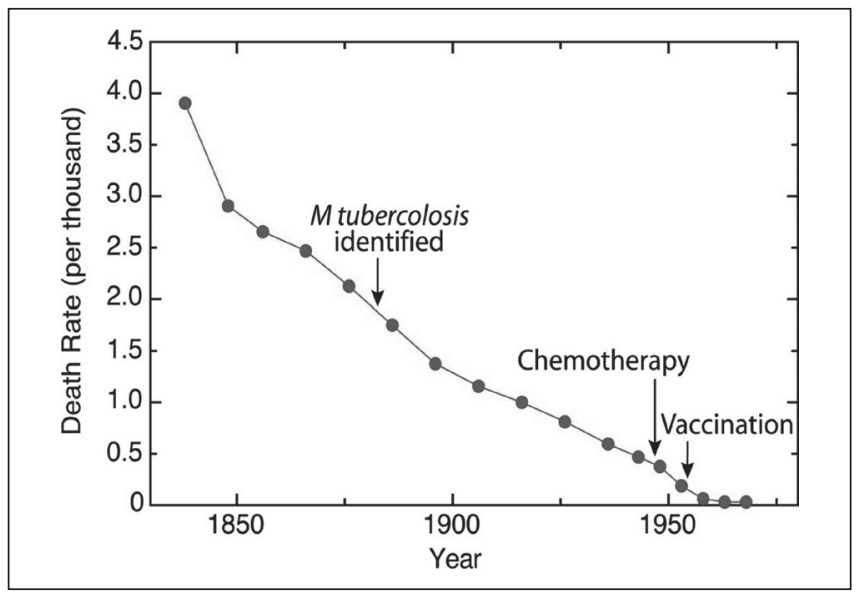

Figure 3: Mortality caused by tuberculosis in England and Wales. Source: McKeown T. The modern rise of population, London: Edward Arnold, 1976. 
Authors like McKeown have strongly argued in favour of improvements in the socio-economic conditions as being the cause of this decline. However, authors like Davies et.al. ${ }^{36}$ assert that improvements in the socio-economic conditions do not explain the whole story. They have explained the biological phenomenon like development of immunity in the populations over long periods of time as having an important role in the decline in the morbidity and mortality due to tuberculosis. However, all authors acknowledge the role of improvements in the soio-economic conditions like poverty, sanitary conditions of living and malnutrition etc. as being crucial. If hunger and malnutrition are widespread, immunity can hardly have a chance to exercise its influence in altering the epidemiology of any disease. Importantly, it is recognized that much of the decline occurred inspite of the modern technological tools and that the latter can only be used effectively to hasten this decline, as also to reduce considerably the current suffering due to the disease.

The rise and fall of tuberculosis is akin to a prolonged epidemic wave, figure (4), covering an expanse of centuries. In most places including India, the wave is now in its last leg i.e. the endemic stage. Even though in India the disease is still at high levels of endemicity, various studies have recorded decline in the incidence and prevalence, as also a change from more severe forms to milder forms of infection. ${ }^{37}$

The foregoing account of the epidemiology of tuberculosis sets the stage for understanding the processes that go into creating the social meaning of tuberculosis.

\section{WHAT GIVES A SOCIAL MEANING TO DISEASE?}

The infectivity, virulence and the potential to cause physical suffering (reversible or irreversible bodily harm/deformity or death) are the factors that determine the initial impact that a communicable disease has on the people. These biological phenomena have social ramifications as well. The more infectious, the more virulent and the more fatal the disease, the more is the fear and the awe that it inspires among the people. The public response to the recent H1N1 flu is the most recent example of this.

The social meaning that accrues to a disease to begin with could vary between being a dreadful curse to being just a minor irritant. However, as the disease plays itself out in the communities and the populations over long periods of time, familiarity with its behavior increases; even without inputs from experts, people modulate their perception of the disease and devise ways to combat it based on their felt experiences of the disease. What these perceptions are; the degree of their rationality and the cultural practices evolved as possible remedies depend on the overall development of knowledge and institutions (educational, cultural, economic, political and medical) in the society and the people's access to these institutions; these in turn are interminably linked to the development of the forces of production and the relations of production engendered by them.

It is pertinent to be reminded that all the modern technological tools to fight disease that man has created today could not have been conceived if the industrial revolution and the social, economic and political revolutions unleashed by it had not happened in Europe. If not Europe, these would have occurred elsewhere, but occurred they must have, for this is a necessary condition of advancement. These developments provided the conditions for the advancement of science and technology to a qualitatively higher plane enabling us to get equipped with tools of modern medicine.

It is said that "what was the cutting edge technology yesterday, is common sense today and what is the state of the art technology today, will be common sense of

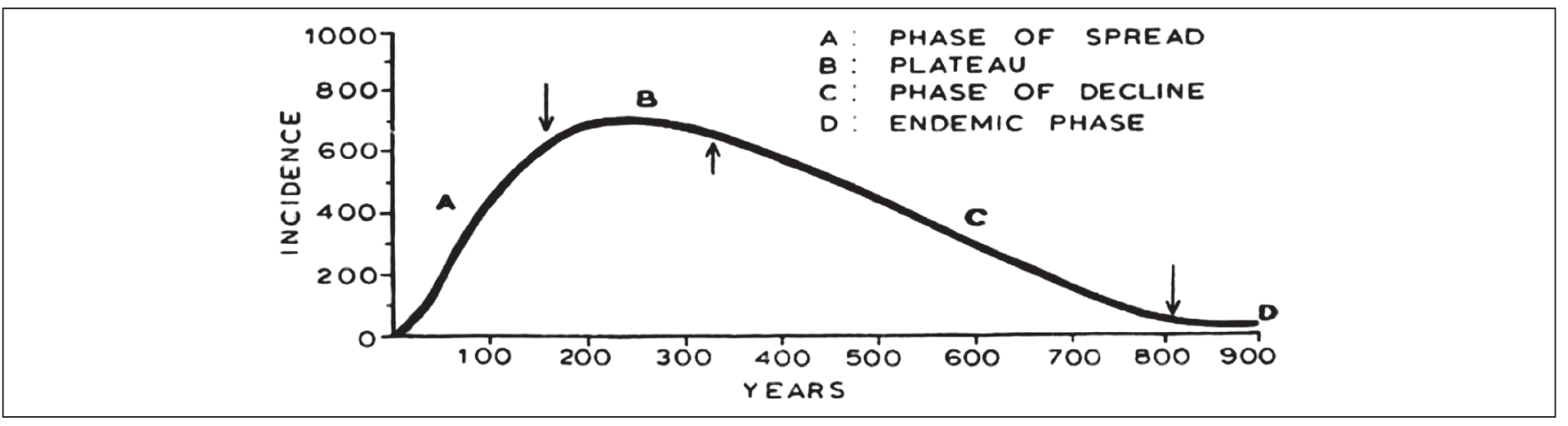

Figure 4: Secular curve of epidemics (semi-diagramatic)

Source: G.D. Gothi. Natural History of Tuberculosis. 
tomorrow." Perhaps the most important lesson to draw from the foregoing is to understand that what is derisively called as the backward and superstitious believes of the people, could perhaps be the most scientific response in their circumstances of life; indeed many of the superstitions continue to afflict even the most educated. The reasons for these are not to be found in the fallibility of individuals themselves, but in whether society at large has outgrown them or not. For example the imbalance between the four humors (black bile, yellow bile, phlegm and blood) was a widely believed scientific explanation of disease among the ancient Greeks and Romans; ${ }^{38}$ however, today this argument shall have few takers. Likewise, its scientific and colonial prowess notwithstanding, bloodletting was among the most common treatment for a variety of diseases in Europe till the very end of the nineteenth century. ${ }^{39}$

In other words it is the difference between two perspectives one, seeing people as illiterate, backward, superstitious lot who need to be educated by learned ones or those in positions of power; or that is it the failure of the social, economic and political system governed by those in positions of power in reaching the benefits of modern knowledge systems and development to the oppressed people?

This interacting complex between the cultural perception of the disease, the health seeking behaviour of the people, their access to health care facilities and the level/nature of advancement of medical technology in the overall milieu of the given productive forces and relations of production is what has been described by Banerji as 'health culture.' The availability of modern anti-tubercular drugs and the wide expanse in treatment facilities has helped change the cultural perception of tuberculosis as a stigmatizing disease almost invariably resulting in death. ${ }^{40}$

The aforementioned conceptualization implies that the social meaning of a disease is a multi-dimensional concept

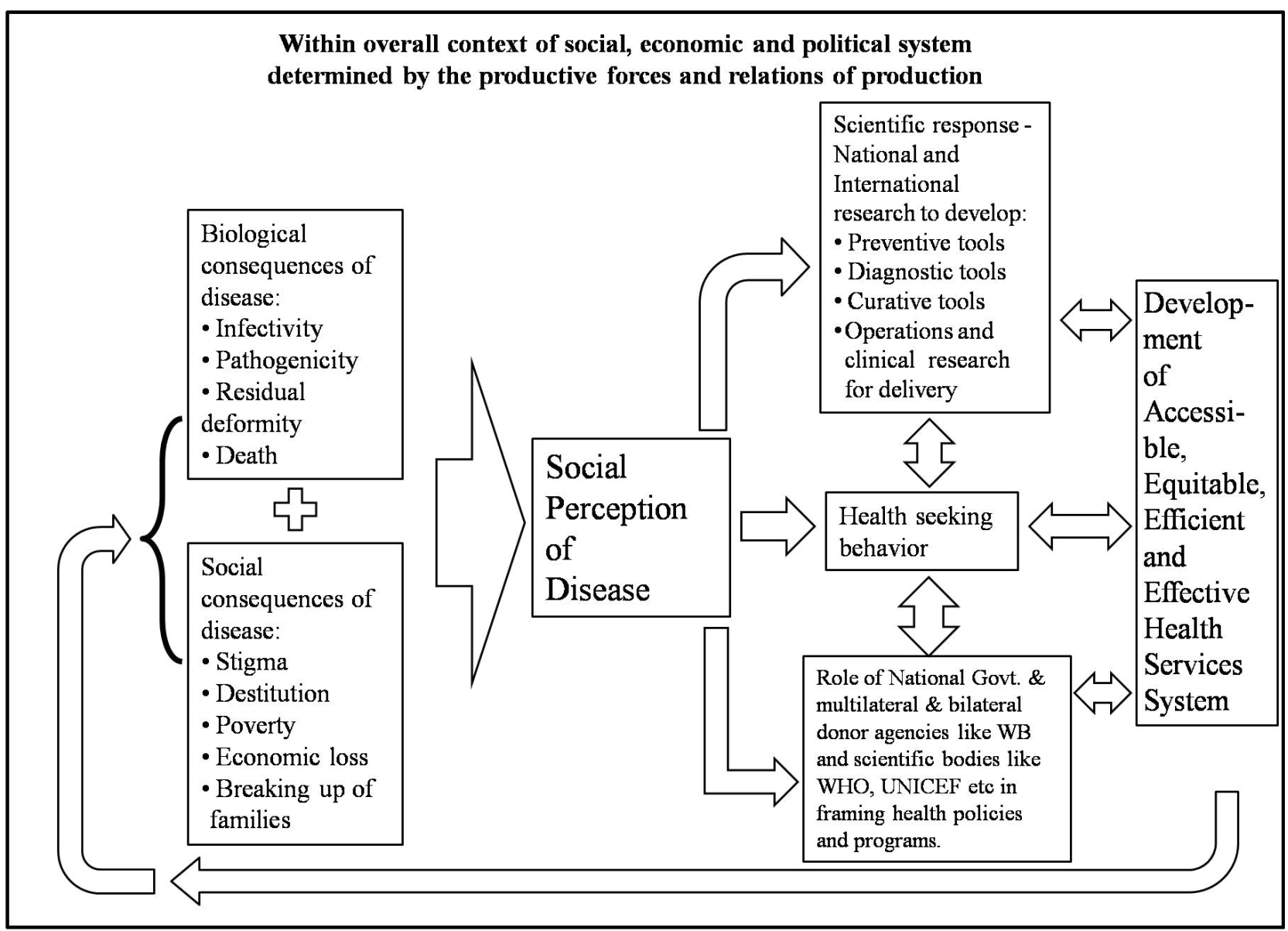

Figure 5: Relationship between the biological and social consequences of the disease, its social meaning, the possible societal responses and the development of health services system.

Note: This diagram represents the scheme that should ideally be followed, but as we shall see later in the article, this may not really be the case in the formulation of health programs. Programs like the family planning program, the universal immunization program, the RNTCP and the pulse polio program are all examples of how these fundamental principles are often violated by our health planners. 
which originates in its biological and social consequences. The response to the biological and social consequences of the disease occurs in the form of treatment seeking behavior of the people, the response of the scientific community (nationally and internationally) and the response of the administrative machinery (the response of the national governments and different bilateral and multilateral international organizations). The scientific and the administrative response should factor in the health seeking behavior of the people and their felt needs. The developments in scientific knowledge regarding the disease and the administrative response in their turn influence the health seeking behavior of the people. Together these three influence the development of the health services system meant to take care of the public health problems posed by various diseases. The degree of equity, accessibility, efficiency and effectiveness of the health services moderate the biological and social consequences of the disease and therefore its social meaning.

Figure (5) above presents a schematic representation of this scheme of things. According to this conceptualization, the people no more remain just the recipients of the services of disease control programs, but also become the motive force and the source of all ingenuity in the designing of a disease control program.

\section{SOCIAL MEANING OF TUBERCULOSIS}

Much of the historiography of tuberculosis that emerges today emerges from Europe. The social meaning of tuberculosis has varied over the period of time in accordance with the extent of its biological and social consequences to the society, the level of understanding regarding its causation at a given point in time and the remedies that were thought to have salubrious effect on the disease.

For much of the medieval and modern history of Europe tuberculosis has been known as "The Captain of All the Men of Death", "The Great White Plague" which had threatened the very survival of the European race. ${ }^{41}$ The analogy with the bubonic plagues of yore that wiped out a third of Europe's population, itself speaks of the terror of the disease in popular perception.

In the absence of any scientific knowledge about the disease, the variety in believes and the therapeutic practices around it was wide and amusing. Seeking change from weather from cold and damp to warm and sunny weather was a common practice. ${ }^{42}$ The believe that the disease spread through contagion from the patients led to formation of elaborate laws to compulsorily burn the belongings of the dead patients and re-plaster the house. On the other hand the belief in some countries that the disease was hereditary obviated the need for any specific action except of course 'balmy air and sunny skies.'3

It is said that "the disease distorted the norms of life and behavior for several generations by killing young adults or ruining their physical and mental health.......Tuberculosis, being so prevalent contributed to the atmosphere of gloom that made possible the success of the "graveyard school" of poetry" in England and France. Keats and Shelly were its proponents in England. This trend changed the meaning of the seasons - autumn that had till then been depicted in literature as a season of "bountiful harvests when men rejoiced health and abundance", came to symbolize "discouragement and destruction of young lives."

There has been this idea; what Greeks called 'spes phthisica', through the history that holds that men of genius are especially prone to get afflicted with TB. ${ }^{45}$ What a disease can do to the psyche and the cultural moorings of a society is reflected in the statement-"In the healthful days to come we may not apprehend the past role of tuberculosis in quickening creative faculties; and by way of compensation for good health we may lack certain cultural joys." ${ }^{46}$ Such was to be the perception through much of the late eighteenth and the early nineteenth centuries in England and France. There was nonetheless intense stigma associated with the disease through this entire period. ${ }^{44}$

The "perverted sentimentalism" of the 'Romantic Era' towards tuberculosis was poised to change with the rapidly evolving industrial societies of Europe which ushered in new kind of productive forces and relations of production in the society. Evolution of new industrial cities with their multitudes of working class cloistered in filthy, sub-human conditions of poverty hardly left any scope for romanticist notions. This change was to find place in the works of the 'realist school' of writers. ${ }^{47} \mathrm{~TB}$ became a disease of human suffering, bereft of any trappings of sentimentalism.

The germ theory of disease, that was to guide the social perception of the disease from the last quarter of the nineteenth century onwards, along with the discovery of Mycobacterium tuberculosis by Robert Koch in 1882, were products of these changed times. These were the times characterized by the growth of the working class consciousness and the class actions of the workers for better conditions of life. ${ }^{48}$ Revolutionary upheavals shook many other countries of Europe through the entire expanse of nineteenth century which helped bring the oppressed masses into the centre stage of social life. ${ }^{49}$ 
There was a gradual realization on part of the national governments for taking better care of the health of the working masses in order to improve their productivity. Improved production was necessary for enhancing trade and increasing profits. Chadwick's Sanitary Report came out in England in 1842. It set the stage of the launching of the 'sanitary era. ${ }^{48}$ Such reforms ensued in other countries as well. ${ }^{50}$ The colonial plunder provided enough resources to carry through the reforms with desired impact. We have already noted the huge decline in the mortality and morbidity due to TB that happened in Europe due to socio-economic development even before any specific public health measures against TB were in vogue.

The improved forces of production under incipient capitalism also led to higher level of scientific enquiry. Even before Koch finally discovered the tubercle bacilli, there was a body of scientific work that made its discovery only a matter of time. The French army surgeon Jean-Antoine Villemin was the first one to demonstrate that phthisis (TB) can be inoculated from man or cow to the rabbit and guinea pig, and can be transmitted from one infected animal to another in unending series in $1865 .{ }^{51}$ Such was the profligacy of scientific work in TB at that time that as many as three German workers are believed to have shown the tubercle bacillus simultaneously, independent of eachother. Koch won the laurels for the masterly and impeccable manner of his presenting the evidence. ${ }^{52}$

With the discovery of the causative organism and the precise method of transmission, the public health measures against TB were no more arbitrary and the research for prevention and cure became more focused. From 1880s onwards TB became a notifiable disease in most European countries. ${ }^{53}$ The invention of tuberculin test and pasteurization of milk occurred in a rather short period of time, BCG immunization against tuberculosis was invented in 1906 and used for the first time on humans in 1921 in France. $^{53}$ Isolation of patients in sanatoria, campaigns against spitting in public, treatments like surgical removal of the affected part of the lung, bronchoscopy and suction, pneumothorax and the discovery of anti- tubercular drugs beginning with streptomycin in 1946, is all a matter of history now.

From about 500 deaths per 100, 000 million people in 1850, the number of TB deaths in Europe dropped to 50 per 100,000 by 1950 . Priority accorded to research in TB by bodies like 'Medical Research Council' of Britain constituted in 1913 further hastened the downward trend. ${ }^{54}$

With the above mentioned scientific developments the morbidity and mortality due to tuberculosis disappeared fast and before long TB in the industrialized world became a thing of the past. The fear and the stigma of the disease were distant memories of another time. Treatment facilities for TB were shut down. The last sanatoria in Europe were shut down in the $60 \mathrm{~s}^{53}$ There was little further research in TB. Little wonder then, that when TB resurged in New York in the late 1980s and early 1990s; it stymied the medical fraternity, the polity and the public alike. ${ }^{55,56}$ That TB appeared with the emerging global pandemic of HIV/ AIDS and multi-drug resistant TB that threatened to expand beyond its usual victims like the homeless, the drug addicts and those in jails to even the well off, multiplied the panic many folds. The tuberculosis epidemic of the New York city in the early 1990s evoked memories of medieval Europe when the public health authorities responded to the epidemic by coercively treating and putting under detention the patients who were likely to be noncompliant, while totally ignoring the socio-economic roots of this resurgence. ${ }^{57}$ This resurgence once again brought TB back on to the global health agenda.

While the industrialized West had had its day with TB; or almost so; the situation in rural Ethiopia, at least until 2004 has been described in the following words - "In rural Ethiopia, neighbors isolate patients with TB. The community makes a fence around the family's house. People deliver water and food to the fence. Fencing a whole neighborhood or village (4-5 houses) also occurs." ${ }^{58}$ In a study done to elucidate the cultural profile of emigrant Ethiopian tuberculosis patients in Seattle-King County, USA, the patients reported the causes of tuberculosis as given in table 2 .

\begin{tabular}{|c|c|c|c|}
\hline Cause & Cause & Cause & Cause \\
\hline $\begin{array}{l}\text { - God } \\
\text { - Draft } \\
\text { - Wind } \\
\text { - Clash of cold and hot air. }\end{array}$ & $\begin{array}{l}\text { - Strong heat } \\
\text { - Sunlight } \\
\text { - Bad sanitation } \\
\text { - Progression from diseases like } \\
\quad \text { pneumonia or common cold }\end{array}$ & $\begin{array}{l}\text { - Mich (caused due to clash of } \\
\text { cold and hot air. } \\
\text { - Contagion by sweat, human } \\
\text { touch and spit in air. } \\
\text { - Fault, bad behaviour and vices. } \\
\text { - Curse, taboo behaviour }\end{array}$ & $\begin{array}{l}\text { - Runs in particular families } \\
\text { - Malnourishment } \\
\text { - Weak immune systems. } \\
\text { - Stress }\end{array}$ \\
\hline
\end{tabular}


These results should surprise us little, for the British in 1820 had an income that was six times the income Ethiopians has in 1992. ${ }^{59}$ The significance of the socio-economic factors in the fight against TB is further highlighted by the fact that while Europe had achieved a TB mortality rate of 50 per 100, 000 in 1950 without the aid of any antibiotics, in India we still have a tubercular mortality upwards of 300 per 100,000, with all the technological interventions of modern science being there at our disposal. We shall talk more on this while discussing the societal response to TB in the second part of this paper.

\section{SOCIAL AND CULTURAL PERCEPTIONS OF TUBERCULOSIS IN INDIA}

Some of the most pioneering studies on the awareness of tuberculosis among the people were conducted by the National Tuberculosis Institute (NTI) as a part of its mandate to design a nationally applicable, socially acceptable and epidemiologically sound tuberculosis control program for the country. In this respect a landmark study was conducted by Banerji and Anderson on the awareness of the symptoms of tuberculosis among the patients. ${ }^{60}$ The whole conceptualization of this study in the form of posing the questions - how many patients were aware of the symptoms of tuberculosis, how many were worried about their symptoms and how many did actually act on the basis of their symptoms; ${ }^{60}$ is a novelty in the entire history of the application of social science concepts in public health research.

The answers to these questions that were thrown up by the study were to be the pivot around which the delivery of National Tuberculosis Control Program was designed. It was found that as many as half of the tuberculosis patients were already seeking treatment for their symptoms from the peripheral health institutions; only to be turned back with a bottle of cough syrup. Another quarter of the patients were worried from their symptoms and as many as $95 \%$ were conscious of their symptoms (chronic cough, fever, pain chest and blood in sputum). ${ }^{61}$ We shall discuss the programmatic implications of these findings in the second part.

The subsequent studies regarding public perception of tuberculosis in India have only reconfirmed or have added to our knowledge without refuting the findings of the above study by Banerji and Anderson.

A study conducted among educated people in the cities of Chennai and Madurai in Tamil Nadu revealed a very high level of awareness among the people wiz the causative agent of TB, its symptoms and mode of transmission.
Though there was relatively less awareness regarding the duration of treatment and sputum disposal. ${ }^{62}$

Another study published in 2002 found the knowledge regarding symptoms, mode of transmission and causation to be fairly good among the rural population of Delhi. Even though there were some differentials in awareness among the educated and the uneducated, the misconception that utensils and food could transmit the disease was found to be equally distributed among both. ${ }^{63}$

Given the epidemiological extent of the disease, there continues to be considerable amount of stigma associated with tuberculosis in India. In a study conducted to find out the community's perception of the disease "fear of losing social status, marital problems and hurtful behaviour by the community" were perceived as common reasons for concealing the disease. ${ }^{64}$ Stigma continues to be a cause for delay in seeking treatment and both males and females continue to carry a "psychological burden of unfulfilled social responsibilities" due to the disease. ${ }^{64}$ Gender is apparently an important determinant of outcomes in TB with females being at considerable disadvantage. Besides more distressing emotional and social symptoms, difficulties in marriage, social isolation, inability to care for children and family etc are some major problems. Allopathic and speciality services are more likely to be accessed by males than females. ${ }^{64,65,66 \text {, and } 67}$

Even though according to one study RNTCP has ostensibly drastically reduced the out of pocket expenses to the patients from Rs 6,000 to Rs 1,400, the unit provider cost remains high at around Rs 2,000. Besides, the social costs of TB remain formidable. Around 11\% of children had to drop from school due to parental tuberculosis, while $20 \%$ had to take up employment, especially if the father had tuberculosis. ${ }^{68}$ However, the whet stone to test the efficacy of a disease control program remains the efficacy with which it addresses the epidemiological aspects of disease progression at the societal level, an aspect that we shall deal with in the second part of the paper.

\section{ACKNOWLEDGEMENT}

Authors would like to acknowledge the concepts taught in the 'Communicable Diseases' course taken by Prof. Ritu Priya at the Centre for Social Medicine and Community Health, Jawaharlal Nehru University. These concepts directly fed into the writing of this manuscript.

\section{REFERENCES}

1. Johan P. Mackenbach. Politics is nothing but medicine at a larger scale: reflections on public health's biggest idea, J Epidemiol Community Health 2009; 63:181-184. 
2. WHO Global TB report quoted in TB India 2010, RNTCP Status Report, Central TB Division, Ministry of Health and Family Welfare, Government of India, p viii.

3. TB India 2010, RNTCP Status Report, Central TB Division, Ministry of Health and Family Welfare, Government of India, p 2.

4. Minutes of the Expert committee meeting to estimate TB burden in India, March 2005. Directorate of Health and Family Welfare, Central TB Division, Government of India, 2005 - quoted in TB India 2010, RNTCP Status Report, Central TB Division, Ministry of Health and Family Welfare, Government of India, p 2.

5. Gopi PG, Subramani R, Santha T, Chandrasekaran V, Kolappan C, et al. Estimation of burden of tuberculosis in India for the year 2000. Indian J Med Res, 2005; 122:243-248

6. TB India 2010, RNTCP Status Report, Central TB Division, Ministry of Health and Family Welfare, Government of India, p 98.

7. TB India 2010, RNTCP Status Report, Central TB Division, Ministry of Health and Family Welfare, Government of India, p 96.

8. Sachin R. Atre1, Abhay M. Kudale1, Sudhakar N. Morankar et. al. Cultural concepts of tuberculosis and gender among the general population without tuberculosis in rural Maharashtra, India. Tropical Medicine and International Health, 2004; Vol. 9 (11):1228-1238.

9. Tuberculosis and Gender, Tuberculosis, WHO, Accessed from http://www. who.int/tb/challenges/gender/en/index.html on the $12^{\text {th }}$ of Oct. 2010.

10. Revised National Tuberculosis Control Program (RNTCP): DOTS Strategy Including DOTS Plus, In National Health Programs of India; National Policies and Legislations Related to Health, Kishore $\mathrm{J}$ (ed), $7^{\text {th }}$ edition, Century Publications, New Delhi, 2007.

11. Raj Narain, S. S. Nair, K. Naganna et. al. Problems in Defining a "Case " of Pulmonary Tuberculosis in Prevalence Surveys. Bull. Wid Hith Org., 1968; 39:701-729.

12. Cedric Northrop, Robt. J. Anderson and Herbert I. Sauer. What Is a Reportable Case of Tuberculosis? Public Health Reports (1896-1970), 1949; Vol. 64 (31): p 961-968.

13. J M Joshi, P Sundaram and RT Kamble. Problems in Laboratory Diagnosis of Tuberculosis, Lung India, 2005; 22:112-115.

14. Nakajima $\mathrm{H}$, Ashida $\mathrm{K}$, Yamasaki $\mathrm{H}$ et. al. Intracranial tuberculoma with spontaneous recovery, Rinsho Shinkeigaku. 1995 May; 35(5):521-5.

15. R.T.D. Emond and G.D. W. Mckendrick. Tuberculosis as a cause transient aseptic meningitis, The Lancet, 1973; Vol. 302 (7823): p 234-236.

16. Tsuyoshi Mitsuishi, Kazumi lida, Seiji Kawana. Papulonecrotic tuberculid with spontaneous remission, Journal of Dermatology, 2006; Vol. 33 (2): p 112-114

17. Brun J, Viallier J, Perrin LF, Juttin P. Disseminated bullous emphysema after spontaneous recovery from miliary tuberculosis; death caused by progressive respiratory insufficiency, J Fr Med Chir Thorac. 1954; 8(5):525-32.

18. National Tuberculosis Institute, Bangalore:Tuberculosis in a rural population of South India - a five -year epidemiological study, Bull.Wld HIth Org, 1974; 51: $p 473$.

19. Baily GVJ, Rupert Samuel GE, Nagpaul DR: A Concurrent Comparison of an Unsupervised Self -administered Daily Regimen and Fully Supervised Twice Weekly Regimen of Chemotherapy in a Routine Out-patient Treatment Programme, Ind. J. Tub., 1974; 21: p 152.

20. Gothi GD, Chakraborty AK, Parthasarathy K and Krishnamurthy VV. Incidence of Pulmonary Tuberculosis and change in Bacteriological Status of cases at Shorter Intervals, Indian J. Med.Res, 1978; 68: p 564.

21. Gothi GD, Savic D, Baily GVJ, Rao KP, Nair SS and Samuel R. Collection and consumption of self-administered anti-tuberculosis drugs under programme conditions, Ind. J. Tub., 1971; 18(4): p 107.

22. Jagota P, Gupta EVV, Sreenivas TR, Parimala N and Chaudhuri K. Operational feasibility of unsupervised intermittent Short Course Chemotherapy regimens at the District Tuberculosis Centre, Ind. J. Tub., 1991; 38: p 55

23. Jagota P, Venkataramana Gupta EV and Channabasavaiah R. Fate of Smear Positive Patients of Pulmonary Tuberculosis at an Urban District Tuberculosis Centre, Five years after Treatment, Ind. J. Tub., 1994; 41: p 223.
24. Jagota P, Sreenivas TR and Parimala N (1996). Improving Treatment Compliance by Observing Differences in Treatment Irregularity, Ind.J. Tub., 1996; 43: p 75.

25. Sophia Vijay, Balasangameshwara VH and Srikantaramu N (1999): Treatment dynamics and profile of tuberculosis patients under the District Tuberculosis Programme (DTP) - A prospective cohort study, Ind. J. Tub., 1999; 46: p 239.

26. Jagota P, Balasangameshwara VH, Jayalakshmi MJ and Islam MM. An Alternative Method of Providing Supervised Short Course Chemoptherapy in District Tuberculosis Programme. Ind. J. Tub., 1997; 44: $p 73$.

27. Jagota P, Gupta EVV, Nagaraja Rao BS, Parimala N and Baily GVJ. The Acceptability and Efficacy of two Regimens of Short Course Chemotherapy under conditions of an urban tuberculosis programme, Ind. J. Tub., 1989; 36: p 18.

28. Suryanarayana L, Vembu K,Satyanarayana C and Rajalakshmi R (1994): Status of Short Course Chemotherapy under National Tuberculosis Programme, Ind. J. Tub., 1995; 41: p 211-221.

29. Thelma Narayan. A violation of citizens' rights: The health sector and tuberculosis. One's understanding of the problem of tuberculosis affects the choice of intervention strategies. IJME, 1999; 7 (3)

30. Jessica Ogden, Gill Walt, Louisiana Lush. The politics of 'branding' in policy transfer: the case of DOTS for tuberculosis control. Social Science and Medicine, 2003; 57:179-188.

31. Nakajima H. Tuberculosis: A Global Emergency, World Health, 1993; 46 (4): p 3.

32. Ian Smith. Stop TB: Is DOTS The Answer? Ind. J. Tub., 1999; 46:81-90.

33. Consensus Statement Multi-drug Resistant and Extensively Drug Resistant TB in India. TB India 2010, RNTCP Status Report, Central TB Division, Ministry of Health and Family Welfare, Government of India, p 76

34. Banerji D. A Social Science Approach To Strengthening India's National Tuberculosis Programme, Ind. J. Tub. 1993, 40: p 61-82.

35. Fine PEM, Carneiro IAM, Milstein JB, Clements CJ. (1999). Issues relating to the use of BCG in immunization programs, A discussion document, WHO, Geneva, 1999.

36. R P O Davies, K Tocque, M A Bellis et. al. Historical declines in tuberculosis in England and Wales: improving social conditions or natural selection? Vesalius, 1999; Vol. 1: p 25-29.

37. G.D.Gothi. Natural History of Tuberculosis, Wander-Tuberculosis Association of India Oration, Delivered on the occasion of the $32^{\text {nd }}$ National Conference on TB and Chest Diseases held at Trivandrum, November 1977.

38. Humorism - from Wikipedia, the free encyclopaedia, dated 13 October, 2010. Available from en.wikipediaq.org/wiki/Humorism, on $19^{\text {th }}$ October 2010.

39. Bloodletting. Science museum brought to life - Exploring the history of medicine. Available from www.sciencemuseum.org.uk/broughttolife/ techniques/bloodletting.aspx, on $19^{\text {th }}$ October, 2010.

40. Debabar Banerji. Starting from the People. Social Sciences and Health Service Development in India; Sociology of Formation of an Alternative Paradigm. Lok Paksh Publishers, New Delhi, 1986: p 99.

41. Rene and Jean Dubos. 'The Captain of All the Men of Death", In "The White Plague:Tuberculosis, Man and Society", Little Brown and Company, Boston, 1953: p 4-16.

42. Rene and Jean Dubos. "Flights from the North Winds", In "The White Plague: Tuberculosis, Man and Society", Little Brown and Company, Boston, 1953: p 18-27.

43. Rene and Jean Dubos. "Contagion and Heredity", In "The White Plague: Tuberculosis, Man and Society”, Little Brown and Company, Boston, 1953 p 28-43.

44. Rene and Jean Dubos. "Consumption and the Romantic Age", In "The White Plague:Tuberculosis, Man and Society", Little Brown and Company, Boston, 1953: p 44-66.

45. Rene and Jean Dubos. "Consumption and the Romantic Age", In "The White Plague:Tuberculosis, Man and Society", Little Brown and Company, Boston, 1953: p 59.

46. Rene and Jean Dubos. "Consumption and the Romantic Age", In "The White Plague:Tuberculosis, Man and Society", Little Brown and Company, Boston, 1953: p 60. 
47. Rene and Jean Dubos. "Consumption and the Romantic Age", In "The White Plague:Tuberculosis, Man and Society”, Little Brown and Company, Boston, 1953: p 66

48. Priti Joshi. The Dual Work of "Wastes" in Chadwick's Sanitary Report, In 'Our Mutual Friend:The Scholarly Pages', Rutgers University. Available from: www2.ucsc.edu/dickens/OMF/joshi.html on $19^{\text {th }}$ Oct. 2010.

49. Jonathan Sperber. The European Revolutions, 1848-1851, Second edition, Cambridge University Press, New York, 2005......History of the Paris Commune. Available from www.marxists.org/history/france/paris-commune/ index.htm on 19th Oct 2010.

50. E. P. Hennock. The urban sanitary movement in England and Germany, 1838-1914: a comparison. Continuity and Change, 2000; 15:269-296. Doi: 10. 1017 / S0268416099003550.

51. Rene and Jean Dubos. "The Germ Theory of Tuberculosis", In "The White Plague: Tuberculosis, Man and Society", Little Brown and Company, Boston, 1953: p 98.

52. Rene and Jean Dubos. "The Germ Theory of Tuberculosis", In "The White Plague: Tuberculosis, Man and Society", Little Brown and Company, Boston, 1953: p 101.

53. Tuberculosis, the deadly companion. FAIRMED: Health for the Poorest. Available from www.fairmed.ch/fm/e/2_3_history.php. on 19th Oct 2010.

54. Medical Research Council (UK). From Wikipedia, the free encyclopaedia. Accessed from en.wikipedia.org/wiki/Medical_Research_Council_(UK) on $19^{\text {th }}$ Oct 2010

55. Lawrence K. Altman. Stymied by Resurgence of TB, Doctors Reconsider a Decades-Old Vaccine. New York Times, $15^{\text {th }}$ Oct 1992.

56. Lessons from New York's tuberculosis epidemic. Tuberculosis is a political as much as a medical problem-and so are the solutions. Editorial, BMJ $1998 ; 317: 616$

57. J D H Porter. From Chaos to Coercion: Detention and the Control of Tuberculosis, J Med Ethics 2002; 28:129.
58. Christine Wilson Owens. Ethiopian Tuberculosis Cultural Profile, Ethnomed. Accessed at ehtnomed.org/clinical/tuberculosis/Ethiopiantuberculosis-cultural-profile on $1^{\text {st }}$ Oct 2010.

59. UNDP, 2009: "Human Development Report 1999", United Nations Development Program, New York, p 38.

60. Banerji, D. and Andersen, S. A Sociological Study of the Awareness of Symptoms Suggestive of Pul- monary Tuberculosis, Bulletin of World Health Or- ganization, 1963, 29 (5), 665.

61. Debabar Banerji. Starting from the People. Social Sciences and Health Service Development in India; Sociology of Formation of an Alternative Paradigm. Lok Paksh Publishers, New Delhi, 1986: p 98.

62. Rajeshwari Ramachandran, Diwakara AM, Sudha Ganapaty et.al. Tuberculosis Awareness Among Educated Public in Two Cities in Tamil Nadu, Lung India, 1995; Vol. 13 (3 and 4): p 108-113

63. R Malhotra, D K Taneja, V K Dhingra et.al. Awareness regarding tuberculosis in a rural population of Delhi, Indian Journal of Community Medicine, 2002; Vol. 27 (2): p 62-67.

64. S. Atrea, A. Kudalea, S. Morankar et.al. Gender and community views of stigma and tuberculosis in rural Maharashtra, India, Global Public Health, 2009; Nov 13:1-16. [Epub ahead of print].

65. Sachin R. Atre, Abhay M. Kudale, Sudhakar N. Morankar et.al. Cultural concepts of tuberculosis and gender among the general population without tuberculosis in rural Maharashtra, India, Tropical Medicine and International Health, 2004; Vol. 9 (11): p 1228-1238.

66. Weiss M G, Somma D, Karim F, et al. epidemiology of TB with reference to gender in Bangladesh, India and Malawi. J Tuberc Dis 2008; 12:837-847.

67. Gosoniu G D, Ganapathy S, Kemp J, et al. Gender and socio-cultura determinants of delay to diagnosis of TB in Bangladesh, India and Malawi. Int J Tuberc Lung Dis 2008; 12:848-855.

68. M Muniyandi, R Ramachandran, R Balasubramanian, P R Narayanan. Socio-economic dimensions of tuberculosis control: Review of studies over two decades from Tuberculosis Research Center, J Commun Dis, 2006; 38 (3):204-215 